\title{
POST-PRINT
}

This is the peer reviewed version of the following article:

Dewitte, L., Granqvist, P., Dezutter, J., Meaning Through Attachment: An Integrative Framework. Psychological Reports. 2018.

which has been published in final form at https://doi.org/10.1177/0033294118799739

Reprinted by permission of SAGE Publications.

\section{Meaning through attachment: An integrative framework}

\author{
Laura Dewitte \\ KU Leuven, University of Leuven, Belgium; Research Foundation Flanders, Belgium \\ Pehr Granqvist \\ Stockholm University, Sweden \\ Jessie Dezutter \\ KU Leuven, University of Leuven, Belgium
}

\section{Corresponding Author:}

Laura Dewitte, Faculty of Psychology and Educational Sciences, KU Leuven, Tiensestraat 102 - box 3717, Belgium.

Email: laura.dewitte@kuleuven.be 


\begin{abstract}
We propose an integrative framework, advancing attachment as a vital factor in the development and maintenance of meaning throughout life. First, early attachment experiences provide a foundation for recognizing patterns and acquiring a sense of order and coherence. Furthermore, interactions with sensitive attachment figures stimulate mentalization capacities and exploration of the inner and outer environment, enabling the formation of complex representations of self, others, and the world, ultimately also molding how individuals appraise meaning in their lives. Second, attachment security can serve as an enduring and powerful resource for handling threats to meaning. When confronted with disruptions to meaning, secure attachment provides a coherent set of representations to fall back on and maintain or regain a firm sense of order and meaning under challenging circumstances. Moreover, by promoting cognitive openness and tolerance of ambiguity, secure attachment facilitates flexible and realistic adjustment of meaning representations when encountering discrepant information.
\end{abstract}

\title{
Keywords
}

Meaning, attachment, development, meaning maintenance 
While meaning has been a topic of keen interest for centuries in philosophy, ethics, and theology, the empirical study of meaning within the psychological discipline emerged only later. Finding important foundations in the work of psychiatrist and Holocaust survivor Viktor Frankl (1968), contemporary meaning literature relates to a broad range of topics. These include assumptive worlds (Janoff-Bulman, 1989, 1992), sense of coherence (Antonovsky, 1987), goal-related coping (Brandtstädter \& Renner, 1990), post-traumatic growth (Calhoun \& Tedeschi, 2014), psychological and eudaimonic well-being (Ryan \& Deci, 2001; Ryff, 1989, 2013), meaning models (Heine, Proulx, \& Vohs, 2006; Park, 2010), purpose in life (McKnight \& Kashdan, 2009), and meaning in life (Heintzelman \& King, 2014; Martela \& Steger, 2016; Steger, 2009).

In the last decennia, especially this latter concept has gained increasing attention in empirical psychology. Recently, a tripartite conceptualization of meaning in life is gaining momentum. In this view, experiencing meaning in life means having a sense that life is 1) coherent/comprehensible, 2) purposeful, and 3) significant (i.e, that it matters and is worth living) (George \& Park, 2016; Martela \& Steger, 2016).

This experience of meaning in life is assumed to arise when current experiences and evaluations of our life are in line with our meaning system, a complex network of global beliefs and goals (Park \& George, 2018). According to the Meaning Maintenance Model (MMM; Proulx, 2013; Proulx \& Inzlicht, 2012; Proulx, Markman, \& Lindberg, 2013), the basis for these higher-order beliefs and goals are the mental representations that human beings construct of associations in their inner and outer world. These representations help them to anticipate and make sense of their experiences and guide their responses (Heine et al., 2006; Proulx \& Inzlicht, 2012). Meaning thus refers to a mental network or system of representations that help us understand ourselves, our environment, and their interrelation (Proulx et al., 2013). These mental representations influence our subsequent expectations, 
perceptions, and interpretations of new experiences. This conceptualization deals with meaning in the broadest sense of the word, at all levels of abstraction, from the meaning of a word, object, gesture or event to the meaning of life itself (Martela \& Steger, 2016; Steger, 2012).

When the network of representations in a meaning system is reliable and hence informative with regard to the way things are and will be, a "feeling of meaning" will arise, serving the function of informing the individual that 'things are making sense', or in other words, that things are coherent and comprehensible (Heintzelman \& King, 2014). Similarly, George and Park (2016) explain how our meaning systems contribute to the three components of meaning in life by consisting of coherent propositions that help individuals to make sense of experiences and life in general (comprehension), by specifying worthwhile goals (purpose), and by containing beliefs about the significance and value of one's life (mattering).

It has been suggested that "stability and coherence in our conceptual systems" is a "fundamental need" for humans (Janoff-Bulman, 1989, p. 115). This is in line with presentday scholars arguing that meaning-making by way of connecting things in our environment and constructing mental representations of these connections is inherent to humans (Heine et al., 2006). However, although humans may be predisposed to make meaning, the skills needed to do so are not simply entirely innate but develop as a function of certain speciestypical experiences (Steger, Hicks, Krueger, \& Bouchard, 2011). Granqvist and Nkara (2017) discussed the idea that genetic predispositions ("nature") are often importantly co-sculpted by environmental factors ("nurture"), including attachment experiences, and they illustrate this point in the context of religious and spiritual development. We argue that in developing meaning, a similar nature-nurture interaction unfolds. We suggest that, although humans seem to have a natural propensity towards making and experiencing meaning, attachment experiences actuate this propensity in important ways, by impacting the development and 
adaptation of meaning systems, the experience of meaning in life and the subjective feeling of meaningfulness.

Below, we delineate this argument in three main sections. In the first section, we elaborate the idea that attachment provides an important foundation for the establishment of meaning by influencing cognitive-affective development and the content of meaning representations, and forms the basis of our global meaning systems and the subjective experience of meaning in life throughout the lifespan. In the second section, we discuss how attachment serves as a lasting resource of meaning in the case of meaning violations. Figure 1 provides an overview of the framework as elaborated in these sections. The third and final section offers concluding remarks. 


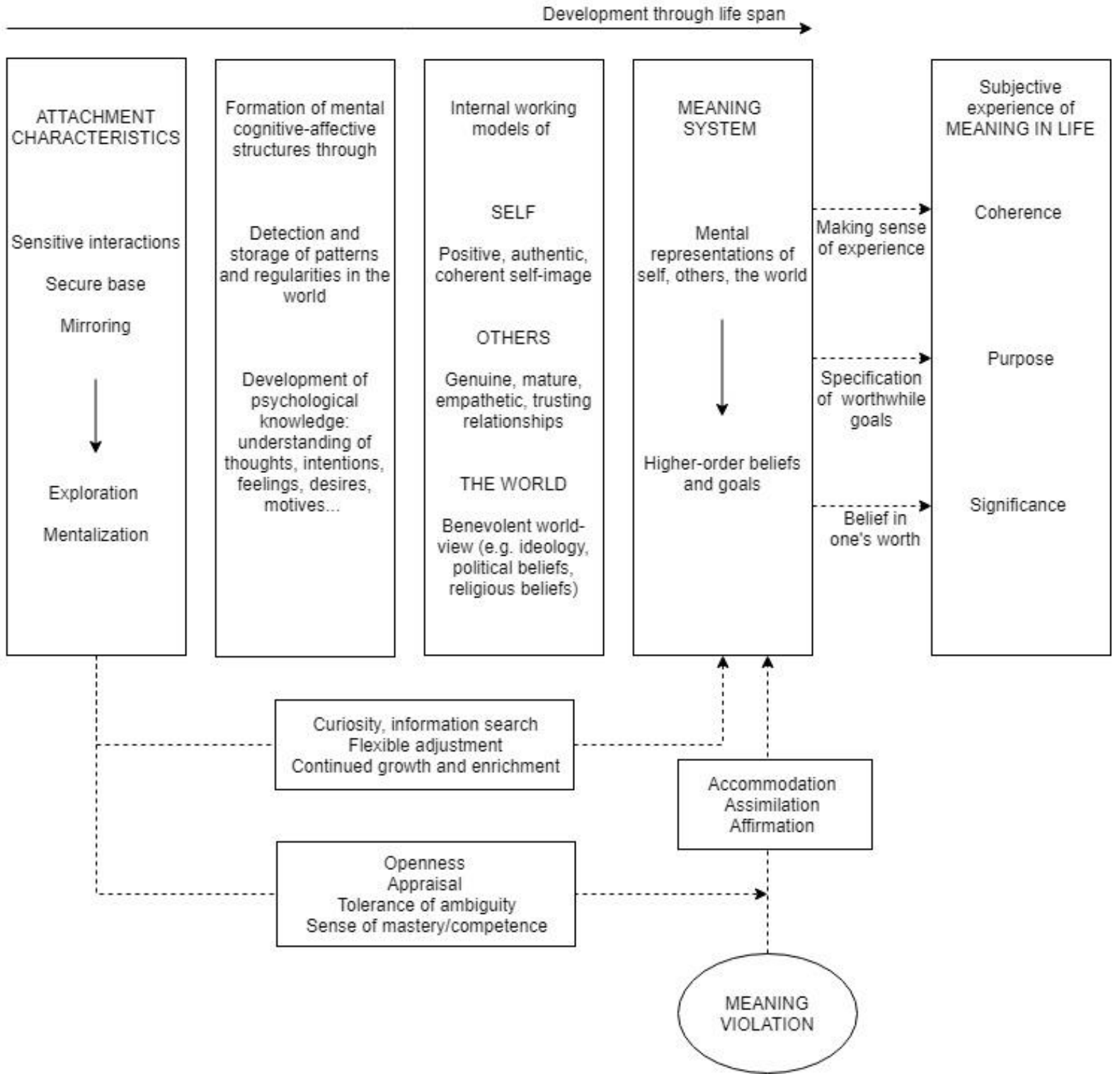

Figure 1. Overview of attachment-meaning framework.

\section{How attachment molds meaning throughout the lifespan}

Attachment behaviors, which are characterized by promoting proximity and protection from caregivers in times of need, are most evident during infancy and early childhood, but remain present in every life stage (Cassidy \& Shaver, 2016; Mikulincer \& Shaver, 2016).

While earlier attachment research often focused on the adverse consequences of an insecure attachment, more recent work has increasingly centered on attachment security as an 
important resource for human growth, well-being, and optimal functioning (Lopez, 2009). Accordingly, in their comprehensive work on adult attachment, Mikulincer and Shaver (2016) call attention to the "optimistic, hopeful, constructive, and actualization-oriented tone of attachment theory" (p. 45).

One of the ways by which attachment in general and attachment security in particular foster a strong and healthy psychological foundation, we argue, is through the contribution of attachment to the construction of meaning. This construction starts at a very basic level, in children's fundamental cognitive acquisitions, such as self-other differentiation, notions of space and time, cause and effect. On a more complex level, a profound meaning experience involves insight into thoughts, feelings, beliefs, intentions, and attitudes. Even more abstractly, children will develop broad ideas, theories, and ideologies about how the world works and how they fit in it. These mental representations coalesce into a broader meaning system, from which the subjective experience of meaning in life can emerge. All of this cognitive-affective growth is highly contingent on the social context in which it develops (Bandura, 1986), of which the attachment context constitutes the first and presumably one of the most influential.

\section{Early childhood acquisitions}

\section{Detecting patterns and accumulating knowledge}

Interactions between caregivers and infants are believed to provide a foundation for the development of neural connections and therefore impact the mind of the developing infant (Siegel, 2001). Similarly, Sroufe (2005, p. 363) proposed that based on early attachment experiences, mental "structures are created which, while changeable, nonetheless are a force in subsequent reactions to experience." Sroufe and colleagues (2005a) supported this with results from a longitudinal study spanning three decades following almost 200 parents and children. They found that many aspects of the children's developmental trajectories, although 
influenced by other care features and the cumulative history of experiences, were predicted by early attachment variations. A history of secure attachment was positively predictive of, among other things, self-reliance, self-esteem, emotion-regulation, ego-resilience, social competence, and adult romantic relationship quality and conflict recovery (Simpson, Collins, \& Salvatore, 2011; Sroufe, 2005; Sroufe, Egeland, Carlson, \& Collins, 2005).

It is now widely accepted that the mental structures formed in infancy and shaped by attachment interactions have a lasting impact on the developing personality, but the development of meaning has received relatively little attention in this regard. Concerning the connection between meaning and early attachment experiences, however, sociologist Peter Marris (1991) made important observations, asserting that "attachment is the first and most crucial relationship through which human beings learn to organize meaning" (p. 78) and in that way, "the management of attachment is the starting point and model for understanding every other kind of order" (p. 79). Early interaction experiences serve as the basis for the child's developing cognitive-affective representations, or internal working models (IWMs) of self and others, which will govern the child's expectations for future social interactions and determine important individual differences in children's behavioral, emotional, and social development (Bretherton \& Munholland, 2008). In order to construct these working models of themselves and attachment figures, which forecast their behavior and responses, children must learn to perceive, understand, and store patterns that enable them to anticipate and interact with the environment in a meaningful way.

One of the very first patterns children learn to detect is the configuration of faces. In this respect, empirical research with neonates suggests that infants discriminate and prefer their primary caregiver's face over that of a stranger, starting already in the first days after birth (Bushnell, 2001; Quinn, Yahr, Kuhn, Slater, \& Pascalis, 2002; Sai, 2005). Thus, it seems that from the very first moments of life, interactions with attachment figures form the starting 
point for our understanding of the world around us.

As the child matures, its knowledge of regularities in the environment expands rapidly. One important aspect in this advancement of knowledge, emphasized by Bowlby (1969) and in line with other leading scholars such as Piaget (1936), White (1959), and later Gibson (1988), is exploration. Through relatively free, undefensive, and curious exploration of and interaction with its surroundings, the child gathers new information and skills, and broadens its cognitive structures. Such exploratory behavior is supported, in particular, by having a secure base in a secure attachment relationship.

\section{Mentalization and representations of self, others, and the world}

Besides stimulating knowledge acquisition in general, social interactions with caregivers will also in particular encourage the development of psychological knowledge in the child. One of the core psychological developments stimulated by attachment, again particularly secure attachment, and important for the construction of complex meaning representations concerns the understanding of mental states. Meaning does not only involve connections between concrete objects in the outer, visible world but also more abstract relations involving covert concepts such as thoughts, emotions, desires, memories (Heine et al., 2006). Accordingly, it has been proposed that an important prerequisite underlying meaning is the ability to reflectively think about and interpret our lives (Martela \& Steger, 2016). In this respect, the concept of mentalization is central, which refers to "the ability to give plausible interpretation of one's own and others' behavior in terms of underlying mental states" (Fonagy, Gergely, \& Jurist, 2002, p. 26). Other constructs used to describe a similar process include theory of mind, social cognition, reflective function, or mindsight (Siegel, 2001). 
The foundations for mentalization can again be traced back to early attachment experiences. The development of this reflective capacity is stimulated in particular by interactions with caregivers who are sensitive to children's needs and emotions, and who effectively mirror the child's experiences and affects. Arising from this is the child's comprehension that they themselves and other people around them have distinct minds and mental states, and the ability to respond to others in light of the interpretation of their beliefs, feelings, perspectives, motives, and desires (Fonagy et al., 2002; Holmes, 2005; Horwitz, 2005; Ringel, 2011).

The extent to which parents facilitate mentalization by responding appropriately to the experiences of the child during social interactions will manifest in the IWMs the child develops. Concerning IWMs of self, early interactions with caregivers are believed to be of indispensable importance. Effective affect-mirroring by caregivers and the mentalization capacities arising therefrom in the child, will enable the child to distinguish the self from others and to acknowledge the specific characteristics of these separate entities (Fonagy et al., 2002). Attachment experiences are a vital source of information for learning about the self and a secure attachment organization is important "for the development of a positive, coherent, and well-organized self-structure" (Mikulincer, 1995, p. 1212), which forms a firm basis for experiencing meaning. Moreover, the possibility to freely explore different options regarding personal choices, beliefs, and values will contribute to the formation of an authentic self as well. Contrarily, attachment insecurity may render children vulnerable to feelings of meaninglessness through an unclear or confused self-image.

Thus, the model of self that an individual develops through caregiver interactions will have important repercussions for his or her sense of meaning. Stable self-views provide a sense of coherence and continuity, and representations of the self serve as central schemas in individuals' knowledge systems and as cornerstones for making predictions about the world. 
This idea was the main starting point of self-verification theory, which claims that people strive for confirmation of their self-views by others, even if these views are negative, precisely because these self-views are so important in guiding their behavior and rendering life coherent and predictable (Swann, 2012). Moreover, on a group level, stable identities of group members lead to "mutual predictability", facilitating effective and meaningful interactions (Swann, 2012, p. 26).

This last element is related to the idea that, besides models of the self, IWMs of others also serve as important mental structures that contribute to the experience of meaning. Since humans are inherently social beings, many meaning representations will be formed in the context of interactions with others. Referring back to the work of early social psychologist Heider (1958), Bretherton and Munholland (2008) point out the importance of more complex cognitive processes in this context:

When we react to others, we do not usually perceive their actions as meaningless movement patterns that have to be laboriously interpreted. Rather, we understand others' behaviors (and we construct working models) in terms of how they make us feel, and what we believe our interaction partners are intending, thinking, perceiving and feeling. (p. 108)

So especially in interaction with others, merely distilling patterns will not be sufficient for a profound meaning experience; a metacognitive understanding of internal processes will also be needed. When parents stimulate reflective capacities by communicating sensitively and using appropriate language referring to emotions and intentions, children become aware of the other's point-of-view and develop the skill to take the other's perspective in relationships into account (Bowlby, 1988; Bretherton \& Munholland, 2008). 
In sum, mentalization stimulated by secure attachment experiences allows children to interpret and predict others' behavior in a meaningful way and enables them to think meaningfully about their own psychological experiences (Fonagy et al., 2002). Consequently, well-developed mentalization abilities stimulate, among other things, a coherent self-view and genuine, mature, empathic interpersonal relationships (Holmes, 2005; Ringel, 2011).

Children with an insecure attachment history, on the other hand, are more prone to develop a distrust towards the outer world and a confused view of themselves, because of inconsistent, rejecting, or frightening experiences that hinder the development of coherent representations (Bowlby, 1988; Sroufe, 2005). In this way, we argue, early attachment experiences will provide an important scaffolding for the development of personal and interpersonal meaning representations. Importantly, IWMs not only involve our self-views and interpersonal experiences but also our general view of how the world works. Although this has received far less attention in the literature than intrapersonal and interpersonal consequences of attachment, one of Bowlby's core insights was that attachment reaches beyond these boundaries and impacts people's broader view of the world as well. Accordingly, Bretherton and Munholland (2008) point out that Bowlby did not regard IWMs as limited to attachment. On the contrary, he wrote about "the working model of the world" (Bowlby, 1973, p. 203) and claimed that, "every situation we meet with in life is construed in terms of the representational models we have of the world about us and of ourselves" (Bowlby, 1980, p. 229). As children grow up, more and more experiences are incorporated into their developing working models of self, others, and the world, which subsequently evolve into more generally applied, increasingly complex mechanisms of behavior, emotion, and distress regulation (Consedine, Fiori, \& Magai, 2012). 


\section{Continued importance of attachment for meaning in adulthood}

\section{Meaning representations: continuation and growth}

The search for and provision of comfort and support in intimate attachment bonds is not limited to childhood but is regarded as an important feature of relationships throughout life (Bowlby, 1988). As people mature, the mental representations shaped by childhood experiences could be viewed as becoming gradually incorporated into a broader meaning system. In this way, internal working models developed early in life continue to affect and mold emotions, beliefs, expectations, and guide behavior throughout adulthood (Bowlby, 1988; Mikulincer \& Shaver, 2016). Therefore, they do not only affect meaning in childhood, but they have an influence on how individuals experience the world throughout life. Marris (1991) points out that this idea can already be found in the first writings of Bowlby (1973), where he emphasizes the long-lasting impact of IWMs formed during the first months of life: “on those models are based all his expectations, and therefore all his plans, for the rest of his life" (p. 369). Uren and Wastell (2002) noted that in this way "meaning is a second-order function in that our assumptions about the world are predicated on our internal representations of attachment" (p. 284). In line with this, Weber and Federico (2007) found that the attachment dimensions of anxiety and avoidance were related to ideological beliefs concerning the safety and harshness of the world, and through these beliefs, attachment scores were indirectly related to political ideologies.

Besides such ideological or political positions, spiritual or religious beliefs constitute an important part of many people's worldview. Granqvist and Kirkpatrick (2013) reviewed evidence showing that attachment security is related to having a more loving, benevolent God image. Furthermore, both past and current attachment security seem linked to a high degree of parent-offspring similarity in many aspects of religiousness and spirituality. The authors hypothesize a dual correspondence process through which these findings might be explained. 
Social correspondence refers to the idea that secure attachment experiences increase the child's receptivity to caregivers' religious or spiritual beliefs. IWM correspondence refers to the idea that secure mental representations of self and others generalize to positive, secure perceptions of God. In line with the latter reasoning, it can be argued more generally, that experiences of responsive, sensitive, affectionate caregiving will bias the individual towards generalized expectations of benevolence in the world (Granqvist \& Nkara, 2017).

Naturally, attachment behavior and IWMs continue to develop and adopt more mature forms, contingent on developmental progression and new experiences. Therefore, the mental representations carried forward from early experiences are not rigid. On the contrary, attachment will also affect the degree of mental flexibility and the adaptability of representations. More specifically, attachment is not only related to active exploration in children, but also in adulthood. Adult attachment security has been associated with higher levels of curiosity and information seeking, higher levels of exploration of career possibilities, and more interest in exploratory activities (Green \& Campbell, 2000; Littman-Ovadia, 2008; Mikulincer, 1997). Moreover, evidence suggests that having a secure base in relationships with trusted others, for instance supportive spouses or counselors, has a positive impact on exploration, goal striving, and personal growth (Feeney \& Thrush, 2010; Feeney \& Van Vleet, 2010; Littman-Ovadia, 2008). Several scholars have noted that characteristics related to exploration - curiosity, information search, and novelty seeking - facilitate the enrichment of cognitive structures and help individuals adapt more easily to changing circumstances (Gibson, 1988; Mikulincer, 1997; White, 1959). Similarly, Kashdan and Steger (2007) state that curiosity has a function to "motivate exploration of the self and world, and expand knowledge and skills" (p. 169) and they suggest that through these growth-oriented mechanisms, curiosity should enhance meaning. In an empirical daily diary study, they found that curiosity was related to growth-oriented behaviors, meaning in life, and life satisfaction, 
and that both state and trait curiosity on a particular day were predictive of greater meaning in life the following day. Kashdan and Steger (2007) speculate that a contributor to these positive outcomes is curious people's higher tolerance of and even attraction towards ambiguous, uncertain activities and situations. Interestingly, such tolerance and approach orientation towards uncertainty have also been attributed to secure attachment (Mikulincer \& Shaver, 2016). Empowered by their secure base, securely attached individuals feel up to handling potentially challenging situations for the benefit of growth and enrichment. Thus, in line with the idea that attachment is not merely a buffer in stressful times but equally a source of growth, the secure base of an attachment bond encourages exploration of the self and the world, contributing to the expansion of knowledge structures and - we argue - meaning.

\section{From working models to meaning in life}

As mentioned, through its contribution to the formation of meaning representations, attachment does not only contribute to an overall sense of comprehensibility by providing the foundation for our apprehension of meaningful connections and order, but also to the subjective experience of meaning in life. Cassidy and Shaver (2016, p. 108) point out that Bowlby "did not intend the concept of working models to be construed in terms of dispassionate mappings of an 'objective' reality. Rather, he regarded emotional appraisals and goal setting as an integral aspect of representation." So besides dealing with coherence and order, IWMs also include the other two components of meaning in life - evaluations of the value and purpose of life (George \& Park, 2016; Martela \& Steger, 2016).

The schemas originating from experiences with attachment figures will impact whether and how meaning in life is experienced. Mikulincer and Shaver (2013) reviewed a broad range of research indirectly supporting the idea that attachment can contribute to a sense of meaning in life through different psychological processes, such as having a sense of 
purpose and direction in life, a unique personal identity, and an individualized faith. As mentioned, mental representations of self as good, worthy, and authentic are a strong point of departure for meaning. Evidence supporting this view has shown that attachment avoidance and anxiety in adulthood are negatively related to self-actualization, partly mediated through diminished self-liking (Otway \& Carnelley, 2013). Furthermore, research suggests that selfalienation might be an important factor underlying the relation between attachment anxiety and life meaning (Lopez, Ramos, Nisenbaum, Thind, \& Ortiz-Rodriguez, 2015). In older age as well, a secure attachment in general relationships or to God has been linked to more selfacceptant views, more positive social relationships views, more personal growth, and more purpose in life (Homan, 2014, 2018). Furthermore, the relation between general attachment security and these outcomes was partly mediated through self-compassion (Homan, 2018).

It appears that from birth on to the latest stages of life, experiences of being safe, recognized, cared for, and valued by others, shape long-term benevolent representations of self and relationship partners, enabling the establishment of a firm sense of meaning in life.

In recent years, some empirical studies on the direct relationship between attachment style and meaning in life have also been undertaken. In a large cross-sectional study, securely attached individuals across different age groups scored higher on presence of meaning in life than insecurely attached individuals (Bodner, Bergman, \& Cohen-Fridel, 2014). With regard to search for meaning in life (i.e., "the strength, intensity, and activity of people's desire and efforts to establish and/or augment their understanding of the meaning, significance, and purpose of their lives" (Steger, Kashdan, Sullivan, \& Lorentz, 2008, p. 200)), secure and dismissive individuals had lower scores than fearful and preoccupied individuals. Similar findings were obtained by Reizer, Dahan, and Shaver (2013), who found that low levels of attachment anxiety and avoidance (i.e., high security) were associated with presence of meaning in life, while especially attachment anxiety was related to searching for meaning in 
life. So based on these results, especially negative models of the self seem related to a higher search for meaning. This might seem contradictory to the idea discussed earlier that security stimulates exploration, however, while exploration is seen as a constructive tendency fostering learning and understanding, search for meaning in combination with a lack of presence of meaning has been related to more negative outcomes (Bodner et al., 2014).

According to Wong (2016), a core feature of meaning in life is self-transcendence, or the extension to dimensions beyond the self - be it other people, or a greater cause or force. Research has shown that especially attachment avoidance is associated with lower levels of self-transcendence, possibly due to avoidant individuals' negative models of others (Otway \& Carnelley, 2013). Furthermore, evidence from two studies (including a direct replication) suggests that meaning in life mediates the relationship between attachment security and satisfaction with life (Yen, 2014). Thus, a possible explanation for insecurely attached individuals' lower well-being is through a lower sense of meaning in life.

\section{Attachment bonds as sources of meaning in life}

From a different perspective, attachment can also support meaning in a direct way, since close interactions with loving and supportive family members and friends are a powerful source of meaning in life as such. Accordingly, research has shown that, throughout the entire lifespan, close affectional bonds involving attachment and caregiving, such as relationships with romantic partners, siblings, parents, or children, remain a vital resource for instilling life with meaning.

For example, across five studies with young adults, Lambert et al. (2010) found consistent evidence for family relationships as the most important source of meaning in life. Moreover, they showed that both family closeness and family support predicted enhanced meaning in life. The authors argue that for young adults, family might be a particularly salient 
source of meaning through its provision of a secure base in a time marked by exploration and instability. Another recent study found similar results (Delle Fave, Brdar, Wissing, \& VellaBrodrick, 2013), with around $84 \%$ of the adult participants spontaneously indicating family as one of the three major sources of meaning in their life. Besides sharing positive moments and fulfilling responsibilities, jointly facing problems and difficulties was often stated as an underlying motive for this source of meaning, clearly indicating the attachment component of these relationships. The authors recognize how family continuously provides the attachment desiderata of security and comfort.

Importantly, not only adults who have had a history of secure attachment to their caregivers in childhood have the ability to find meaning in close and supportive relationships. Ainsworth (1985) noted that many individuals, such as older siblings, other relatives, teachers, mentors, coaches, priests, or therapists, have the potential to act as surrogate attachment figures when parents fail to provide a secure base. In his compensation theory of attachment, Kirkpatrick (1992) added God and other higher powers to this list of potential substitutes. Such surrogate and symbolic attachment relationships might provide a powerful corrective or even transformative experience for individuals with an insecure attachment history.

Up until now, we have identified attachment as an important foundation for the experience of meaning, influencing the formation and content of meaning throughout life. Unfortunately, longitudinal studies directly investigating the interrelation of attachment and meaning over time are lacking. However, a study by Olsson, McGee, Nada-Raja, and Williams (2013) spanning 32 years, might give some preliminary evidence for the suggested pathway through the lifespan. They found that social connectedness in childhood was predictive of social connectedness in adolescence, measured among others by attachment to 
parents and friends, which in turn predicted adult well-being, measured among others by meaning (i.e. sense of coherence).

\section{Attachment and management of meaning violations}

A comprehensive account of how humans deal with violations to their meaning system has been offered by Proulx and Inzlicht (2012), drawing on earlier theories of compensatory reactions to discrepant experiences (e.g., Festinger, 1962) and as a continuation of their work on the Meaning Maintenance Model (MMM; Heine et al., 2006). As noted, the MMM implies that human beings have a basic need to identify meaningful associations in the inner and outer world. Moreover, according to the MMM, the aversive feeling resulting from a disruption to these expected relations in new experiences will motivate compensation efforts in order to reduce aversive arousal and restore a sense of meaning.

For the current discussion, three compensation behaviors are of special interest. Besides biasing the interpretation of an experience so that it matches pre-existing understandings (assimilation) or revising existing representations to account for the experience (accommodation), people might also affirm other existing mental representations to alleviate negative feelings (affirmation) (Proulx \& Inzlicht, 2012). Importantly, the confirmation of alternative meaning relations does not necessarily take place within the same domain as where the meaning violation was experienced. The authors call this process, in which violations in one domain can lead to meaning reaffirmation in another, fluid compensation.

Heine et al. (2006) discussed evidence of fluid compensation between four major domains (i.e., self-esteem, certainty, belongingness, and symbolic immortality), but noted that this list of domains is not meant to be exhaustive. According to the authors "meaning is sought in domains that are most easily recruited, rather than solely in the domain under 
threat." (p. 90). We argue that for secure individuals, attachment is another domain that should be readily appealed to.

\section{Attachment and meaning maintenance efforts}

Following the reasoning above, attachment can be a powerful resource to maintain or regain meaning under threat. Zooming in on the compensation behaviors mentioned above, attachment might have an influence on all three.

Regarding assimilation and accommodation, we return to Marris (1991), who argued that children use two attachment resources to invoke their caregivers: "making a fuss" or "working the system" (p. 79). The former refers to behaviors expressing discontent or frustration and a need for attention. The latter refers to a growing understanding of "how to comply with the requirements of a relationship to achieve a desired result" (Marris, 1991, p. 79). According to the author, these two attachment resources are reflected in the strategies used by adults when confronted with stressors: "Throughout our lives, asserting our will and seeking knowledge remain the two often competing means by which we create order, predictability, and meaning” (p. 79). This dichotomy can also be recognized in the compensation behaviors of assimilation and accommodation, respectively. When individuals handle meaning violations by assimilating conflicting information within existing representations, they are essentially asserting their beliefs. In contrast, accommodating the meaning system by incorporating new information reflects an updating of knowledge structures. So following this reasoning, these two broad strategies of handling meaning violations find their origin in attachment behavior and, as indirectly suggested by Marris (1991), we can expect that individuals with a secure history are more likely to have the learning response (i.e., accommodation) as a default strategy. 
A similar idea was advanced by Mikulincer (1997), who argued that insecurely attached individuals might be more prone to cognitive closure or "the extent to which people prefer secure knowledge and reject new information that may create confusion and ambiguity" (p. 1219). According to attachment theory, secure individuals' strong personal identity and sense of autonomy should make them more confident in handling ambiguity and confusion, and more flexible in opening up their cognitive structures for new information, while insecure individuals might be more easily overwhelmed by the threat of uncertainty, and deal with this by guarding their mental representations against discrepant information (Mikulincer \& Shaver, 2016).

In line with theory, attachment security has been associated with lower preference for order and predictability; lower discomfort with ambiguity; a reduced primacy effect (i.e., the tendency to favor information provided first while disregarding information provided afterwards when making a judgment); and with less strong ethnic stereotyping (GreenHennessy \& Reis, 1998; Mikulincer, 1997). Security is also linked to higher openness to counterarguments to one's own position regarding certain topics (Jarvinen \& Paulus, 2016), a more positive evaluation of different types of out-groups, and more favorable ratings of individuals challenging one's cultural worldview (Mikulincer \& Shaver, 2001).

Overall, empirical studies clearly indicate a link between attachment security (both as dispositional attachment style and as momentarily boosted) and openness towards information-challenging meaning representations. As hinted by some authors, level of threat appraisal might be an important mediator, with secure individuals being more equipped to deal with information that is more obviously threatening to important meaning representations. For example, Mikulincer (1997) found no differences across attachment styles in self-rated decisiveness and close-mindedness, which may indicate that insecure individuals are not so much reluctant towards new information per se, but perhaps specifically 
towards information that triggers uncertainty and ambiguity, such as disruptions to important meaning representations. Relatedly, Mikulincer and Shaver (2001) showed that the association between temporarily boosted security and out-group evaluation was partially mediated by lower threat appraisal of differences in worldview beliefs and values. Thus, participants boosted with security evaluated out-group members more positively, in part because they felt less threatened by their differing worldview. These findings suggest that felt security can be effectively invoked to ameliorate feelings of threat when meaning representations are violated.

Our own research on meaning in life in elderly offers some preliminary direct evidence for the link between attachment and meaning maintenance through appraisal: based on interviews with older adults we found that both attachment avoidance and anxiety were negatively predictive of presence of meaning (while controlling for their interrelationship). Importantly, for attachment avoidance this link was partly mediated through diminished positive reappraisal of difficult events in life (personal data). Avoidantly attached individuals might have a particularly hard time to engage in reappraisal, because this form of meaningmaking requires acknowledging and focusing one's mind on matters that avoidant individuals prefer to deny. For secure individuals on the other hand, the positive models of self, others, and the world that they possess, support more constructive attention to and reappraisals of threats (Mikulincer \& Shaver, 2016). This is in line with Homan (2018), who found that older adults with a secure attachment experienced more personal growth and sense of mastery and competence in life, suggesting they felt more equipped to handle life experiences and challenges with confidence and in an active, self-fulfilling way.

Again, however, we shouldn't overgeneralize this to mean that only secure individuals have the potential to successfully handle threats. One study found that the dismissive adults in the sample (i.e., high scores on avoidance, low scores on anxiety) were in fact more likely to 
employ reappraisal and display resilience, which mediated a pathway to higher well-being; a pattern similar to the secure individuals in the sample (Karreman \& Vingerhoets, 2012). So it seems that in certain circumstances, dismissing individuals are able to employ their own particular strengths to deal with stressors and regulate their emotions.

The argument that attachment security promotes accommodation of meaning representations does not imply that accommodation is always the best response. In many circumstances, it would be inefficient to take into account every tiny sample of ambiguous or conflicting information. Thus, assimilation is a valuable process to deal with presumably trivial or minimal meaning violations and to maintain an overall sense of stability. However, this becomes problematic when rigidity in interpreting information impairs individuals from adapting optimally and realistically to the environment, especially in circumstances where this might be detrimental for the individual or for others.

Besides stimulating the accommodation of meaning representations, attachment might be a particularly strong source for fluid compensation through affirmation when meaning is disrupted. Especially in the case of security, attachment provides a coherent set of representations to fall back on. This means that, in addition to seeking feelings of comfort and security, individuals might also turn to attachment relationships to attenuate the arousal of disruptions to meaning and to affirm the feeling that things are orderly and making sense. Not much empirical research is available in this area, but in a preliminary study with undergraduates, participants asked to write an essay on life's potential meaninglessness reported higher desire for romantic closeness and intimacy afterwards compared to those writing about life's meaningfulness or a different neutral topic (Shaver \& Mikulincer, 2012). These results suggest that the attachment system was activated by the threat to meaning, potentially in part because participants were looking for affirmation of their attachmentrelated meaning representations to maintain a sense of meaning. 


\section{Violation of attachment-related meaning representations}

Summarizing the above, in the event of meaning violations, attachment can be employed as a fluid compensation mechanism and can serve as a catalyst of other compensation processes, most evidently accommodation. Importantly, meaning violations will also occur in the context of attachment-related representations. That is, individuals may at times experience meaning violations with regard to their expectations towards attachment figures. For example, a secure husband who turns to his spouse for advice but receives an insensitive response is likely to experience negative feelings because of this unanticipated reaction. According to the $\mathrm{MMM}$, this is not only because of the insensitive reaction per se, but also because of the discrepancy between the husband's expectations of his spouse's reaction (based on his attachment representations) and the spouse's actual reaction.

Following this reasoning, attachment-related threats should evoke similar meaningrestoring processes as other threats to meaning. This idea is in line with attachment theory, which posits that during social encounters, a reciprocity takes place between internal working models and the novel information provided by a specific situation (Weinfield, Sroufe, Egeland, \& Carlson, 2008). On the one hand, expectations derived from internal working models will bias the processing of new information in light of previous experiences (cf. assimilation) but, at the same time, internal working models can also be updated to a certain extent to account for conflicting information (cf. accommodation). The ease with which working models can be adjusted, however, varies across attachment styles. As securely attached individuals show less defensive reactions towards the incorporation of discrepant information, we can expect secure individuals to also handle violations to attachment-related expectations more constructively and to feel less easily unsettled by them. 
Some studies focusing on romantic adult attachment indeed indirectly indicate an association between attachment and meaning-maintenance processes in light of disruptions to attachment expectations. Mikulincer and Arad (1999) demonstrated that the aforementioned findings regarding attachment and cognitive openness can be extended to close interpersonal relationships: secure participants as well as participants primed with security were more likely to revise their evaluation of their romantic partner when asked to take into account hypothetical information about the partner's behavior that was contrary to their expectations. While this effect was independent of the positive or negative valence of the incongruent behavior, secure individuals were more likely to actively recall positively incongruent behavior than negatively incongruent behavior. This suggests that secure individuals are able to flexibly adjust their expectations, without actively dwelling on negative information and hence maintaining an overall positive model of the partner.

Across four studies, Gaines et al. (1997) similarly found that securely attached individuals reported a greater tendency to react to disruptive behavior of their partners in a constructive way, while insecure individuals were more likely to act destructively. That is, when faced with behavior of the partner that elicited concern, secure individuals were more inclined to work through the problem in a way that benefited the relationship. This again suggests that secure individuals not only accommodate their relational representations in a realistic way; they also validate their existing belief that the relationship is built on a firm, secure base that allows them to efficiently tackle issues together.

The disruptive behavior of insecure individuals in the aforementioned studies can in fact also be interpreted as meaning-maintaining behavior. There is some evidence that in conflict situations between partners, women high in rejection anxiety were more likely to exhibit behavior that led to actual separation (Downey, Freitas, Michaelis, \& Khouri, 1998). Thus, these women exhibited behavior that elicited a situation in line with their expectations, 
namely rejection. Although the authors of the study propose that the negative behavior was likely an expression of negative emotions, they also acknowledge the possibility that the behavior is a way to maintain predictability. Following this argument, disruptive behavior of insecurely attached individuals in the context of partner conflict can in part be understood as an extreme example of meaning-maintenance, in which insecure expectations are confirmed by exhibiting behavior that sustains the expectations.

\section{Concluding remarks}

As is evident in the arguments made in this paper, we believe that the potentially farreaching consequences of attachment on meaning should not be underestimated. However, as always, some words of caution are in order. First, it should be noted that neither a history of attachment insecurity nor insecure adult attachment relationships at present should be seen as condemning an individual to meaninglessness, just as attachment security should not be seen as a guarantee for a flourishing, meaningful life. Many accounts on attachment seem to have as their premise that a secure attachment equals successful outcomes (Mikulincer \& Shaver, 2016). We as well suggest that attachment security can serve as facilitator of meaning processes and a protective factor when meaning is threatened. Similarly, attachment insecurity can be a vulnerability factor for some individuals, but in no way does it predetermine the course of a person's life (Bowlby, 1988; Sroufe, 2005). On the contrary, individuals who despite challenging circumstances are able to overcome and transcend previous insecure chapters of their lives, might find the deepest sense of meaning.

Second, we do not claim that attachment is the single most important mechanism contributing to meaning, nor that attachment theory provides a comprehensive meaning framework. A host of other psychological and social mechanisms play their role in shaping the unique meaning system of each individual. We do claim, however, that attachment 
deserves increased attention in this context, in part because attachment starts to form so early in development and has such important implications for later developmental trajectories.

Third, it is warranted to question why we should focus specifically on attachment processes and relationships, as opposed to more general personal relationships. Although close and warm relationships in general are essential to living a fulfilling life for most individuals, there is something very distinct and irreplaceable to the affectional bonds we have with people so central in our lives (Marris, 1991), who provide us with the feeling of not being alone in hardship, of having a secure base that makes us feel confident to pursue our life goals and a safe haven to come home to when needed. Especially when these relationships are secure, we believe they may foster meaning in a very specific way, by shaping a coherent life narrative, stimulating exploration and openness, and providing a deep-rooted, lasting resource for feelings of meaningfulness.

Fourth and relatedly, we have approached attachment as a relatively stable characteristic, as an underlying global attachment style. However, people also possess specific attachment models that can vary across relationships or contexts. This is important because, although someone might have a generally secure attachment style, contextual factors can play an important role in whether attachment is used as a resource or not. Furthermore, individuals with a more insecure overall attachment style can also benefit from situational factors evoking a sense of felt security, as has been demonstrated in priming studies (e.g., Mikulincer \& Arad, 1999; Mikulincer \& Shaver, 2001).

Notably, this latter observation can be important when considering the clinical implications of the framework outlined. With regard to psychotherapy, attachment might be an important factor to take into account in case of existential doubts. Further, establishing a secure base in therapy might be a powerful tool to stimulate openness to corrective experiences and enhancement of meaning. 
Both theory and empirical studies from both meaning and attachment literatures support the framework outlined in this paper. Nonetheless, studies testing predictions directly derived from the framework - both regarding the meaning-constructing and meaningmaintaining role of attachment - are of course needed. Especially longitudinal research tracking the dynamic interplay between attachment and meaning constructs over time is required. We believe that such research can build on the integration we have provided and holds much promise to further promote our understanding of meaning throughout the lifespan and the factors underpinning and sustaining it.

\section{Funding}

This work was supported by the Research Foundation Flanders (1109417N) and the John Templeton Foundation (grant no 51897).

\section{Declaration of conflicting interests}

The authors declare that there is no conflict of interest.

\section{References}

Ainsworth, M. D. S. (1985). Attachments across the life span. Bulletin of the New York Academy of medicine, 61(9), 792.

Antonovsky, A. (1987). Unraveling the mystery of health: How people manage stress and stay well. San Fransisco, CA: Jossey-Bass.

Bandura, A. (1986). Social foundations of thought and action: A social cognitive theory. Englewood Cliffs: Prentice-Hall, Inc.

Bodner, E., Bergman, Y., \& Cohen-Fridel, S. (2014). Do attachment styles affect the presence and search for meaning in life? Journal of Happiness Studies, 15(5), 1041-1059. doi:10.1007/s10902-013-9462-7 
Bowlby, J. (1988). A secure base: Clinical applications of attachment theory. New York, NY: Routledge

Brandtstädter, J., \& Renner, G. (1990). Tenacious goal pursuit and flexible goal adjustment: explication and age-related analysis of assimilative and accommodative strategies of coping. Psychology and Aging, 5(1), 58-67. doi:10.1037/0882-7974.5.1.58

Bretherton, I., \& Munholland, K. A. (2008). Internal working models in attachment relationships: Elaborating a central construct in attachment theory. In J. Cassidy \& P. R. Shaver (Eds.), Handbook of attachment: Theory, research, and clinical applications (2nd ed., pp. 102-127). New York, NY: Guilford Press.

Bushnell, I. W. R. (2001). Mother's face recognition in newborn infants: Learning and memory. Infant and Child Development, 10(1-2), 67-74. doi:10.1002/icd.248

Calhoun, L. G., \& Tedeschi, R. G. (2014). Handbook of posttraumatic growth: Research and practice. New York, NY: Psychology Press.

Cassidy, J., \& Shaver, P. R. (2016). Handbook of attachment: Theory, research, and clinical applications (3rd ed.). New York, NY: Guilford Press

Consedine, N., Fiori, K., \& Magai, C. (2012). Regulating emotion expression and regulating emotion experience: Divergent associations with dimensions of attachment among older women. Attachment \& Human Development, 14(5), 477-500. doi:10.1080/14616734.2012.706433

Delle Fave, A., Brdar, I., Wissing, M. P., \& Vella-Brodrick, D. A. (2013). Sources and motives for personal meaning in adulthood. Journal of Positive Psychology. doi:10.1080/17439760.2013.830761

Downey, G., Freitas, A. L., Michaelis, B., \& Khouri, H. (1998). The self-fulfilling prophecy in close relationships: Rejection sensitivity and rejection by romantic partners. Journal 
of Personality and Social Psychology, 75(2), 545-560. doi:10.1037/00223514.75 .2 .545

Feeney, B. C., \& Thrush, R. L. (2010). Relationship influences on exploration in adulthood: The characteristics and function of a secure base. Journal of Personality and Social Psychology, 98(1), 57. doi:10.1037/a0016961

Feeney, B. C., \& Van Vleet, M. (2010). Growing through attachment: The interplay of attachment and exploration in adulthood. Journal of Social and Personal Relationships, 27(2), 226-234. doi:10.1177/0265407509360903

Festinger, L. (1962). A theory of cognitive dissonance (Vol. 2). Stanford: Stanford University Press.

Fonagy, P., Gergely, G., \& Jurist, E. L. (2002). Affect regulation, mentalization, and the development of the self. New York, NY: Other Press.

Frankl, V. E. (1968). Man's search for meaning: An introduction to logotherapy. London: Hodder and Stoughton.

Gaines, S. O., Reis, H. T., Summers, S., Rusbult, C. E., Cox, C. L., Wexler, M. O., . . Kurland, G. J. (1997). Impact of attachment style on reactions to accommodative dilemmas in close relationships. Personal Relationships, 4(2), 93-113. doi:10.1111/j.1475-6811.1997.tb00133.x

George, L. S., \& Park, C. L. (2016). Meaning in life as comprehension, purpose, and mattering: Toward integration and new research questions. Review of General Psychology. doi:10.1037/gpr0000077

Gibson, E. J. (1988). Exploratory behavior in the development of perceiving, acting, and the acquiring of knowledge. Annual Review of Psychology, 39(1), 1-42.

Granqvist, P., \& Kirkpatrick, L. A. (2013). Religion, spirituality, and attachment. In K. I. Pargament, J. J. Exline, \& J. W. Jones (Eds.), APA handbook of psychology, religion, 
and spirituality (Vol 1): Context, theory, and research (pp. 139-155). Washington, DC American Psychological Association.

Granqvist, P., \& Nkara, F. (2017). Nature meets nurture in religious and spiritual development. British Journal of Developmental Psychology. doi:10.1111/bjdp.12170

Green-Hennessy, S., \& Reis, H. T. (1998). Openness in processing social information among attachment types. Personal Relationships, 5(4), 449-466. doi:10.1111/j.14756811.1998.tb00182.x

Green, J. D., \& Campbell, W. K. (2000). Attachment and exploration in adults: Chronic and contextual accessibility. Personality and Social Psychology Bulletin, 26(4), 452-461. doi:10.1177/0146167200266004

Heider, F. (1958). The psychology of interpersonal relations. New York, NY: Wiley.

Heine, S. J., Proulx, T., \& Vohs, K. (2006). The meaning maintenance model: On the coherence of social motivations. Personality and Social Psychology Review, 10(2), 88110. doi: 10.1207/s15327957pspr1002_1

Heintzelman, S. J., \& King, L. A. (2014). Life is pretty meaningful. American Psychologist, 69(6), 561. doi:10.1037/a0035049

Holmes, J. (2005). Preface In J. Bowlby (Ed.), A secure base: Clinical applications of attachment theory (pp. xiii-xx). New York, NY: Routledge

Homan, K. J. (2014). Symbolic attachment security and eudemonic well-being in older adults. Journal of Adult Development, 21(2), 89-95. doi:10.1007/s10804-013-9182-6

Homan, K. J. (2018). Secure attachment and eudaimonic well-being in late adulthood: The mediating role of self-compassion. Aging \& Mental Health, 22(3), 363-370.

Horwitz, L. (2005). The capacity to forgive: Intrapsychic and developmental perspectives. Journal of the American Psychoanalytic Association, 53(2), 485-511. doi:10.1177/00030651050530021401 
Janoff-Bulman, R. (1989). Assumptive worlds and the stress of traumatic events: Applications of the schema construct. Social Cognition, 7(2), 113-136. doi:10.1521/soco.1989.7.2.113

Janoff-Bulman, R. (1992). Shattered assumptions: Towards a new psychology of trauma. New York, NY: Free Press.

Jarvinen, M. J., \& Paulus, T. B. (2016). Attachment and cognitive openness: Emotional underpinnings of intellectual humility. The Journal of Positive Psychology, 1-13. doi:10.1080/17439760.2016.1167944

Karreman, A., \& Vingerhoets, A. J. J. M. (2012). Attachment and well-being: The mediating role of emotion regulation and resilience. Personality and Individual differences, $53(7), 821-826$.

Kashdan, T., \& Steger, M. (2007). Curiosity and pathways to well-being and meaning in life: Traits, states, and everyday behaviors. Motivation and Emotion, 31(3), 159-173. doi:10.1007/s11031-007-9068-7

Kirkpatrick, L. A. (1992). An attachment-theory approach psychology of religion. The International Journal for the Psychology of Religion, 2(1), 3-28.

Lambert, N. M., Stillman, T. F., Baumeister, R. F., Fincham, F. D., Hicks, J. A., \& Graham, S. M. (2010). Family as a salient source of meaning in young adulthood. The Journal of Positive Psychology, 5(5), 367-376. doi:10.1080/17439760.2010.516616

Littman-Ovadia, H. (2008). The effect of client attachment style and counselor functioning on career exploration. Journal of vocational behavior, 73(3), 434-439.

Lopez, F. G. (2009). Adult attachment security: The relational scaffolding of positive psychology. In C. R. L. Snyder, S. J. (Ed.), Oxford handbook of positive psychology (pp. 405-416). New York, NY: Oxford University Press. 
Lopez, F. G., Ramos, K., Nisenbaum, M., Thind, N., \& Ortiz-Rodriguez, T. (2015). Predicting the presence and search for life meaning: Test of an attachment theory-driven model. Journal of Happiness Studies, 16(1), 103-116.

Marris, P. (1991). The social construction of uncertainty. In C. M. Parkes, Stevenson-Hinde, J., \& Marris, P (Ed.), Attachment across the life cycle (pp. 77-90). London: Routledge.

Martela, F., \& Steger, M. F. (2016). The three meanings of meaning in life: Distinguishing coherence, purpose, and significance. The Journal of Positive Psychology, 1-15. doi:10.1080/17439760.2015.1137623

McKnight, P. E., \& Kashdan, T. B. (2009). Purpose in life as a system that creates and sustains health and well-Being: An integrative, testable theory. Review of General Psychology, 13(3), 242-251. doi:10.1037/a0017152

Mikulincer, M. (1995). Attachment style and the mental representation of the self. Journal of Personality and Social Psychology, 69(6), 1203-1215. doi:10.1037/00223514.69.6.1203

Mikulincer, M. (1997). Adult attachment style and information processing: Individual differences in curiosity and cognitive closure. Journal of Personality and Social Psychology, 72(5), 1217-1230. doi:10.1037/0022-3514.72.5.1217

Mikulincer, M., \& Arad, D. (1999). Attachment working models and cognitive openness in close relationships: A test of chronic and temporary accessibility effects. Journal of Personality and Social Psychology, 77(4), 710. doi:10.1037/0022-3514.77.4.710

Mikulincer, M., \& Shaver, P. R. (2001). Attachment theory and intergroup bias: Evidence that priming the secure base schema attenuates negative reactions to out-groups. Journal of Personality and Social Psychology, 81(1), 97-115. doi:10.1037/0022-3514.81.1.97

Mikulincer, M., \& Shaver, P. R. (2013). Attachment orientations and meaning in life. In J. A. Hicks \& C. Routledge (Eds.), The experience of meaning in life: Classical 
perspectives, emerging themes, and controversies (pp. 287-304). Dordrecht, The Netherlands: Springer.

Mikulincer, M., \& Shaver, P. R. (2016). Attachment in adulthood: Structure, dynamics and change (2nd ed.). New York, NY: Guilford Press.

Olsson, C. A., McGee, R., Nada-Raja, S., \& Williams, S. M. (2013). A 32-year longitudinal study of child and adolescent pathways to well-being in adulthood. Journal of Happiness Studies, 14(3), 1069-1083.

Otway, L. J., \& Carnelley, K. B. (2013). Exploring the associations between adult attachment security and self-actualization and self-transcendence. Self and Identity, 12(2), 217230.

Park, C. L. (2010). Making sense of the meaning literature: An integrative review of meaning making and its effects on adjustment to stressful life events. Psychological Bulletin, 136(2), 257-301. doi:10.1037/a0018301

Park, C. L., \& George, L. S. (2018). Lab-and field-based approaches to meaning threats and restoration: Convergences and divergences. Review of General Psychology, 22(1), 73. doi:10.1037/gpr0000118

Piaget, J. (1936). La naissance de l'intelligence chez l'enfant (2nd ed.). Neuchâtel: Delachaux et Niestlé.

Proulx, T. (2013). Beyond mortality and the self: Meaning makes a comeback. In K. D. Markman, T. Proulx , \& M. J. Lindberg (Eds.), The psychology of meaning. Washington, DC: American Psychological Association.

Proulx, T., \& Inzlicht, M. (2012). The five "A"s of meaning maintenance: Finding meaning in the theories of sense-making. Psychological Inquiry, 23(4), 317-335. doi:10.1080/1047840X.2012.702372 
Proulx, T., Markman, K. D., \& Lindberg, M. J. (2013). Introduction: The new science of meaning. In K. D. Markman, T. Proulx , \& M. J. Lindberg (Eds.), The psychology of meaning. Washington, DC: American Psychological Association.

Quinn, P. C., Yahr, J., Kuhn, A., Slater, A. M., \& Pascalis, O. (2002). Representation of the gender of human faces by infants: A preference for female. Perception, 31(9), 11091121.

Reizer, A., Dahan, D., \& Shaver, P. R. (2013). The contributions of attachment and caregiving orientations to living a meaningful life. Psychology, 04(12), 1039-1045. doi:10.4236/psych.2013.412151

Ringel, S. (2011). Developing the capacity for reflective functioning through an intersubjective process. Clinical Social Work Journal, 39(1), 61-67. doi:10.1007/s 10615-009-0246-9

Ryan, R. M., \& Deci, E. L. (2001). On happiness and human potentials: A review of research on hedonic and eudaimonic well-being. Annual Review of Psychology, 52(1), 141-166. doi:10.1146/annurev.psych.52.1.141

Ryff, C. D. (1989). Happiness is everything, or is it? Explorations on the meaning of psychological well-being. Journal of Personality and Social Psychology, 57(6), 1069. doi:10.1037/0022-3514.57.6.1069

Ryff, C. D. (2013). Psychological well-being revisited: Advances in the science and practice of eudaimonia. Psychotherapy and Psychosomatics, 83(1), 10-28. doi:10.1159/000353263

Sai, F. Z. (2005). The role of the mother's voice in developing mother's face preference: Evidence for intermodal perception at birth. Infant and Child Development, 14(1), 2950. doi:10.1002/icd.376 
Shaver, P. R., \& Mikulincer, M. (2012). An attachment perspective on coping with existential concerns. In P. R. Shaver \& M. Mikulincer (Eds.), Meaning, mortality, and choice: The social psychology of existential concerns (pp. 291-307). Washington, DC: American Psychological Association.

Siegel, D. J. (2001). Toward an interpersonal neurobiology of the developing mind: Attachment relationships, "mindsight", and neural integration. Infant Mental Health Journal, 22(1-2), 67-94. doi:10.1002/1097-0355(200101/04)22:1<67::AIDIMHJ3>3.0.CO;2-G

Simpson, J. A., Collins, W. A., \& Salvatore, J. E. (2011). The impact of early interpersonal experience on adult romantic relationship functioning: Recent findings from the Minnesota Longitudinal Study of Risk and Adaptation. Current Directions in Psychological Science, 20(6), 355-359. doi:10.1177/0963721411418468

Sroufe, L. A. (2005). Attachment and development: A prospective, longitudinal study from birth to adulthood. Attachment \& Human Development, 7(4), 349-367. doi:10.1080/14616730500365928

Sroufe, L. A., Egeland, B., Carlson, E. A., \& Collins, W. A. (2005). Placing early attachment experiences in developmental context. In K. E. Grossmann, K. Grossmann, \& E. Waters (Eds.), Attachment from infancy to adulthood: The major longitudinal studies (pp. 48-70). New York, NY Guilford Press.

Steger, M. F. (2009). Meaning in life. In S. J. Lopez \& C. R. Snyder (Eds.), Oxford handbook of positive psychology (pp. 679-687). New York, NY: Oxford University Press.

Steger, M. F. (2012). Making meaning in life. Psychological Inquiry, 23(4), 381-385. doi:10.1080/1047840X.2012.720832 
Steger, M. F., Hicks, B. M., Krueger, R. F., \& Bouchard, T. J. (2011). Genetic and environmental influences and covariance among meaning in life, religiousness, and spirituality. The Journal of Positive Psychology, 6(3), 181-191.

Steger, M. F., Kashdan, T. B., Sullivan, B. A., \& Lorentz, D. (2008). Understanding the Search for Meaning in Life: Personality, Cognitive Style, and the Dynamic Between Seeking and Experiencing Meaning. Journal of Personality, 76(2), 199-228. doi:10.1111/j.1467-6494.2007.00484.x

Swann, W. B. (2012). Self-verification theory. In P. A. M. Van Lange, A. W. Kruglanski, \& E. T. Higgins (Eds.), Handbook of theories of social psychology (Vol. 2, pp. 23-42). London: SAGE Publications Ltd.

Uren, T. H., \& Wastell, C. A. (2002). Attachment and meaning-making in perinatal bereavement. Death Studies, 26(4), 279-308. doi:10.1080/074811802753594682

Weber, C., \& Federico, C. M. (2007). Interpersonal attachment and patterns of ideological belief. Political Psychology, 28(4), 389-416. doi:10.1111/j.1467-9221.2007.00579.x

Weinfield, N. S., Sroufe, L. A., Egeland, B., \& Carlson, E. (2008). Individual differences in infant-caregiver attachment: Conceptual and empirical aspects of security. In J. Cassidy \& P. R. shaver (Eds.), Handbook of attachment: Theory, research, and clinical applications (2nd ed.). New York, NY: Guilford Press.

White, R. W. (1959). Motivation reconsidered: The concept of competence. Psychological Review, 66(5), 297. doi:10.1037/h0040934

Wong, P. T. P. (2016). Meaning-seeking, self-transcendence, and well-being Logotherapy and existential analysis: Proceedings of the Viktor Frankl Institute Vienna, Volume 1 (pp. 311-321). Switzerland: Springer International Publishing. 
Yen, C. L. (2014). Why are people with insecure attachments unhappy? The mediation of meaning in life. International Journal of Psychology, 49(5), 404-408. doi:10.1002/ijop.12038 